\title{
Diazinon Affects the Cytoarchitecture of Seminiferous Epithelium in Rat Testis
}

\author{
Damodar D. ${ }^{1, *}$, Urban J. A. D’Souza ${ }^{1}$, Anupam Biswas ${ }^{1}$, Shankara Bhat ${ }^{2}$ \\ ${ }^{1}$ Department of Physiology, KVG Medical College and Hospital, Sullia, Karnataka, India \\ ${ }^{2}$ Yenepoya Medical College and Hospital, Yenepoya University, Mangalore, Karnataka, India
}

\begin{abstract}
Chemical pollution and reproductive toxicity has a close association leading into a possible infertility. Testicular toxicity induced by chemicals is easy to evaluate since it has a pool of differentiating cells of different stages in the seminiferous epithelium. Most of the pesticide related preclinical studies have heavily dependent upon investigations on sperm density, abnormal sperm percent, reproductive hormone levels etc. Most of the toxins, in addition may affect the seminiferous tubular architecture, harmony as well as supporting cells such as Sertoli cells. Diazinon and its adverse sperm toxic effects are documented earlier but its effects on seminiferous tubules are less recorded. The present study was designed to evaluate the effect of oral administration of diazinon ( $6 \mathrm{mg}, 7.5 \mathrm{mg}$ and $10 \mathrm{mg} / \mathrm{kg}$ body weight/day for 5 and 30days) on acetylcholine esterase activity, histological aspects of testes and seminiferous tubular morphometry (STD \& SEH). Acetylcholine esterase activity was significantly decreased as a sign of toxicity, the dose tested. The STD and SEH were significantly decreased in all the 30days diazinon exposed groups. Histologically testes showed vacuoles, disruption and sloughing of basal germinal epithelium. This study confirms that diazinon disrupts cytoarchitectural components which may interfere with spermatogenesis.
\end{abstract}

Keywords Diazinon Toxicity, Seminiferous Tubular Diameter, Seminiferous Epithelial Height

\section{Introduction}

Organophosphorus insecticides (OPs) are widely used since few decades in agricultural practices and pest control in public places. Though they are known to cause environmental pollution and untoward health problem to the public at large, usage of pesticide is a general practice. Exposure to both animal and mankind occurs via food, water and inhalation leading to acute and chronic health problems and cases of human and animal poisonings were recorded ${ }^{1,2}$. Global concerns raised in recent years over the potential health hazards that arise from exposure to chemicals are alarming. Most of the human systems are highly vulnerable to these chemicals and has resulted in central nervous system, immune, cardiorespiratory malfunctions. Epidemiological studies revealed that in the last 50 years the reproductive quality in human had been decreased with a threat to fertility ${ }^{3}$. Chemical pollution and testicular toxicity has been an issue of great concern in the last decades. In our previous reports we found a decline in sperm count with an increased sperm abnormality in rats exposed to low doses of diazinon. Diazinon and most of the other OPs have adverse toxic effects on reproductive system and they were known to inhibit

* Corresponding author:

damdevas@yahoo.com (Damodar D.)

Published online at http://journal.sapub.org/ajbe

Copyright (C) 2012 Scientific \& Academic Publishing. All Rights Reserved cholinesterase activity ${ }^{4,5}$. Though OP compounds are cytotoxic to the spermatogenic cell cycles, their untoward toxicity in the seminiferous tubular cell architecture is not reported so far. Hence the objective of the present study was to evaluate the serum cholinesterase activity to assess the toxicity and histological aspects of testis and seminiferous tubular morphometric and cyto-architectural components on exposure to low doses of diazinon.

\section{Material and Methods}

Diazinon (o, o-diethylo-2-isopropyl-6methylpyrimidine4-yl phosphorothioate) of $99 \%$ purity was generously provided by Devidayal Agro Chemicals Mumbai, India. $\mathrm{LD}_{50}$ of diazinon in rat is $300 \mathrm{mg} / \mathrm{kg}$. In this study, the doses used were $0 \mathrm{mg}, 6 \mathrm{mg}, 7.5 \mathrm{mg}$ and $10 \mathrm{mg} / \mathrm{kg}$ body weight for 5 and 30days exposure duration in adult male Wistar albino rats.

Adult male Wistar albino rats (13 - 16 weeks old) weighing approximately $200-230$ grams obtained from the K.V.G. Medical College, Sullia, D.K, animal house were used. The rats were maintained in polypropylene cages $(29 \times 22 \times 14 \mathrm{~cm})$ with paddy husk bedding under the laboratory conditions of $28 \pm 2^{\circ} \mathrm{C}$ temperature and $50 \pm 5$ / humidity for two weeks for acclimatization. In each cage, maximum of three rats were housed to avoid any stress due to overcrowding. The rats had access to food and water ad libitum (laboratory pellets; Gold Mohur-Lipton India Ltd.). All the 
rats were in good health. Prior to administration of test substance (diazinon), rats were assigned to each group by randomization of body weights. All experimental procedures and animal maintenance were done under the guidelines of Institutional Ethics Committee for the use of animals in the experiment.

\section{Experimental Groups and Treatment Shedule}

After two weeks of acclimatization period, rats were randomly divided into experimental $(n=36)$ and control $(n=6)$ groups as follows,

Group I: (Control) $0 \mathrm{mg}$ diazinon $/ \mathrm{kg}$ body weight

Group II: $6 \mathrm{mg}$ diazinon $/ \mathrm{kg}$ body weight for $5 \mathrm{~d}$.

Group III: $7.5 \mathrm{mg}$ diazinon/kg body weight for $5 \mathrm{~d}$.

Group IV: $10 \mathrm{mg}$ diazinon/kg body weight for $5 \mathrm{~d}$.

Group V: $6 \mathrm{mg}$ diazinon/kg body weight for 30d.

Group VI: $7.5 \mathrm{mg}$ diazinon/kg body weight for $30 \mathrm{~d}$.

Group VII: $10 \mathrm{mg}$ diazinon/kg body weight for 30d.

Each non fasted rat received the appropriate dose in the morning between 10:00 and 10:30 h by oral gavage. The exact dosage for each rat was corrected for individual body weight every third day by appropriate volume adjustment. The control group received $0.5 \mathrm{ml}$ saline once in a day and treatment group received diazinon single dose daily for 5 days and 30 days separately. Rats were sacrificed after $24 \mathrm{~h}$ of last treatment day by cervical dislocation. Blood samples were collected and laporatomy was performed, reproductive organs were exposed. The epididymis were carefully separated and the testes were fixed in fresh alcoholic Bouin's fluid for 8 hours, processed by dehydration in different concentrations of alcohol, cleared with xylol and embedded in paraffin and $5 \mu \mathrm{m}$ sections were cut and stained with haematoxylin and eosin. The tissue sections were observed under a light microscope for qualitative and quantitative changes in the seminiferous tubules. The seminiferous tubular diameter(STD) and seminiferous epithelial height(SEH) of 10 cross sections per animal were measured including basement membrane by ocular micrometer calibrated with stage micrometer(Erma optical, Japan) ${ }^{6}$. For each animal, 200 tubules were examined and the average was calculated. Blood samples were left till clotting and centrifuged at 3000 rpm for $10 \mathrm{~min}$. The sera were used for activities of cholinesterase assay.

STATISTICAL ANALYSIS: Statistical analyses were based on comparing the data between the diazinon groups with control group. Data are expressed as Mean \pm S.D. The statistical significance was determined using one way analysis of variance followed by Kruskal Wallis test. The level of significance was $\mathrm{p}<0.05$.

\section{Results}

Histological evaluation of seminiferous tubules in the control group (group I) revealed normal architecture with circular or elliptical tubules with intact basal lamina. Tubular epithelium showed germ cells along with Sertoli cells which were layered in concentric manner and tubular lumen was usually with normal spermatozoa (Fig1). Seminiferous tubules of group V, group VI and group VII rats showed disorganization of basal lamina, disruption of basal germ cells and sloughing of cells (Fig 2, 3) at the junction between basal compartment containing the spermatogonia and early-stage primary spermatocytes and adluminal compartment containing later stage primary spermatocytes and all subsequent stages of sperm cells. Usually this junctions form the physical blood-testis barrier, which creates a specialized safe microenvironment for developing sperm. Diazinon exposure showed distorted shape of seminiferous tubules with vacuoles and intraepithelial spaces in the epithelium (fig 4). There was a decline in number of germ cells with accumulation of cellular debris in the lumen of tubules. Treatment with diazinon in rats resulted in significant inhibition of serum cholinesterase $(p<0.01)$ activity. There were reduction in the STD and SEH in all treated groups, with significant reduction $(\mathrm{p}<0.01)$ in group V, group VI and group VII (Table 1).

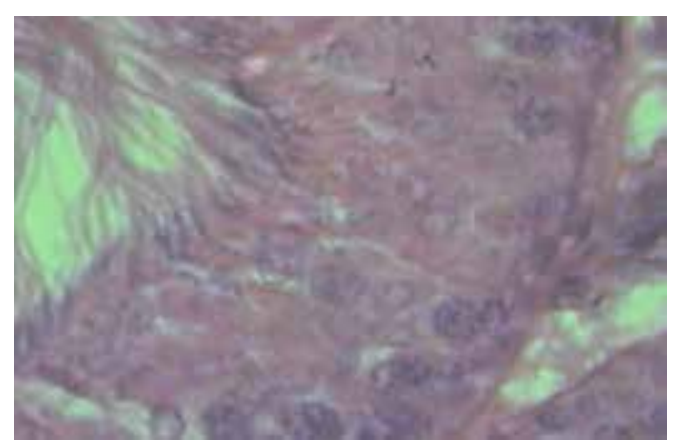

Figure 1. Normal architecture of seminiferous tubular epithelium with developing germ cells
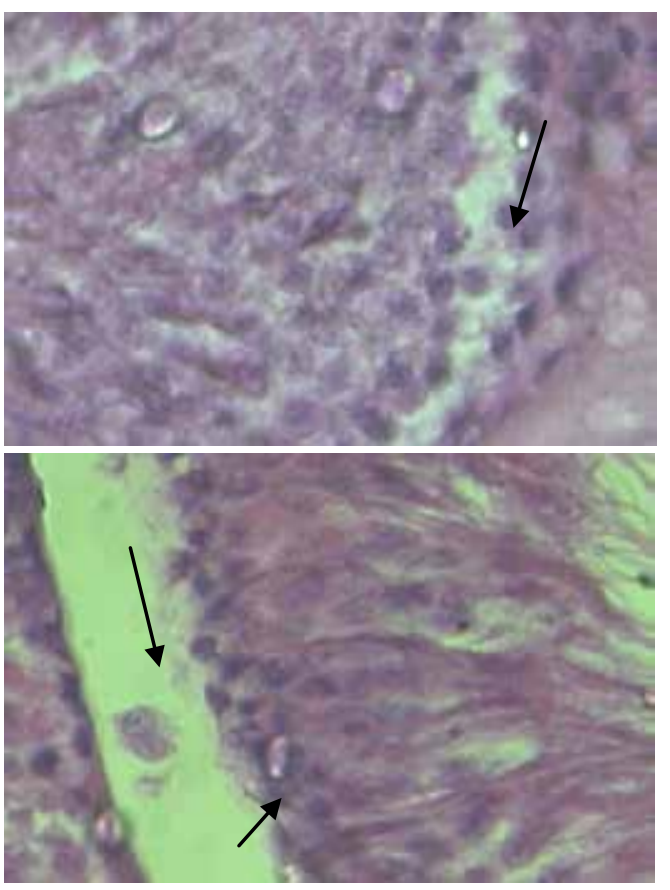

Figure 2 \& 3. Disrupted basal lamina and sloughing of germ cells (arrow) 


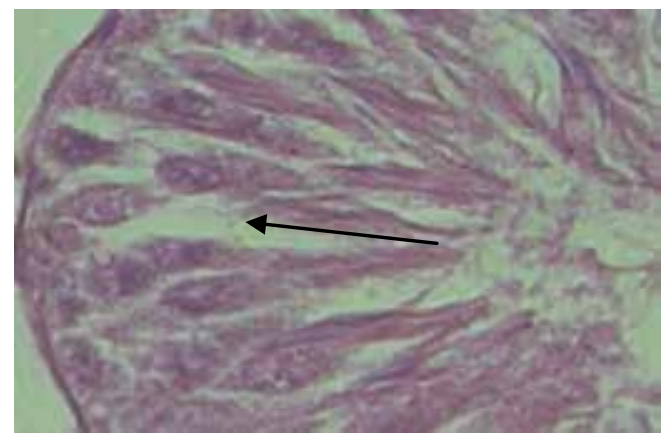

Figure 4. Number of germ cells declined and intraepithelial spaces producing vacuoles (arrow)

Table 1. Effect of diazinon on serum cholinesterase activity and seminiferous tubular diameter (STD) and seminiferous epithelial height (SEH)

\begin{tabular}{|c|c|c|c|c|c|}
\hline Duration & Group & Dose & Serum cholinesterase activity & STD & SEH \\
\hline 5 days & I (control) & 0mg & $733.13 \pm 10.08$ & $298.47 \pm 2.17$ & $86.88 \pm 5.71$ \\
& II & $6 \mathrm{mg}$ & $473.14 \pm 43.02^{*}$ & $293.00 \pm 5.48$ & $85.33 \pm 6.15$ \\
& III & $7.5 \mathrm{mg}$ & $399.51 \pm 26.62^{*}$ & $292.67 \pm 9.00$ & $85.00 \pm 6.06$ \\
& IV & $10 \mathrm{mg}$ & $256.21 \pm 9.44^{*}$ & $289.73 \pm 12.40$ & $85.33 \pm 6.50$ \\
& & & & & \\
& & & & & \\
& V & $6 \mathrm{mg}$ & $470.95 \pm 37.84^{*}$ & $274.60 \pm 7.81^{*}$ & $62.30 \pm 4.15^{*}$ \\
& VI & $7.5 \mathrm{mg}$ & $258.29 \pm 10.77^{*}$ & $269.67 \pm 9.50^{*}$ & $61.00 \pm 4.14^{*}$ \\
& VII & $10 \mathrm{mg}$ & $273.84 \pm 49.53^{*}$ & $266.67 \pm 12.55^{*}$ & $56.23 \pm 4.25^{*}$ \\
\hline
\end{tabular}

*P $>0.01$, control vs diazinon exposed group.

\section{Discussion}

Organophosphate pesticides are known for their adverse reproductive toxicity in both male and females. Pesticides lead into male reproductive toxicity by a decrease in rate of spermatogenesis, a decline in androgen levels, abnormal sperm and a direct cell killing action. When low dose of pesticides are introduced, they may result in oxidative stress resulting in spermatogenic cellular necrosis or apoptosis. Most of the past facts reveal a decrease in sperm count and increase in sperm abnormality. Our previous reports also confirm a decline in spermatogenesis on exposure to a low dose of diazinon. Testis is the major organ that is present outside the body and chances of exposure to pesticide related chemicals is more at least among the farming population. Since seminiferous tubular epithelium and its cytoarchitecture is a main source of sperm production, adverse effects of diazinon on seminiferous tubular cell harmony is not documented yet in the literature. Since cellular harmony and tubular histology need to be assessed to confirm the toxicity of diazinon, we attempted to study the qualitative and quantitative aspects microscopically. The quantitative measurements of tubular diameter and epithelial height basically are an indicator of normal epithelial cytoarchitecture with harmonious germinal cell associations. A decrease in tubular diameter and epithelial height indicates that, the cell associations in the germ epithelium were disturbed with sloughing of cells due to the effect of toxicity. Similar results were reported earlier on exposure to methyl parathion and anticancer drugs such as 5-florouracil and tamoxifen ${ }^{7,8}$. The germ cell sloughing reflects functional damage to the basal membrane and intraepithelial cells. The proposed mechanism contributing to sloughing is due to the disruption of microtubules. The destruction of micro tubule-vimentin filaments which are required as an anchoring device for germ cells also lead to exfoliation of germinal epithelium, ${ }^{9,10,11}$. The results of present study confirm that, diazinon and its metabolites destroy the microtubule vimentin filament there by leading into the sloughing of germinal epithelium into the lumen of the tubules. Another cause for sloughing of germinal epithelium is lack of testosterone support on germ cells. Our experiment showed that even before destruction of Leydig's cells, germ cells undergo sloughing indicating the damage to the microtubule network which is most probable cause of germ cell sloughing. Diazinon may also probably enhance the oxidative stress, altering the antioxidant enzymes which again may have adverse effects on normal cell association. As a result of sloughing, there was a significant decrease in epithelial height as well as tubular diameter in the treated rat testis compared to the control. Overall there was a significant adverse effect of diazinon on testicular cell harmony and further may contribute negatively to the fertility as the number of spermatogonia available for the production of sperm are decreased as well as the immature developing cells were lost due to the sloughing. This study concludes that, diazinon adversely affects the spermatogenic cell populations due its toxicity on microtubular filaments as a result there is a decrease in seminiferous tubular diameter and epithelial height with a significant sloughing of active cells.

\section{REFERENCES}

[1] Mogadamnia AA and Abdollahi M. An epidemiological study of poisoning in northern Islamic Republic of Iran. East Mediterr Health J.2002; 8:88-94.

[2] Abdollahi M, Ranjbar A, Shadnia S, Nikfar S, Reizaic OF. 
Insecticides and oxidative stress: a review. Med Sci Monit 2004; 10 (6):141-147.

[3] Carlsen E, Giwercman A, Keiding N, Skakkebaek NE. Evidence for decreasing quality of semen during the past 50 years. British Medical Journal 1992; 305; 609-613.

[4] Quistad GB, Sparks SE, Segall Y, Nomura DK, Casida JE. Selective inhibitors of fatty acid amide hydrolase relative to neuropathy target esterase and acetylecholinesterase: toxicological implications. Toxicol Appl pharmacol 2002; 179:57-63.

[5] Dikshith TS, Behari JR, Datta KK, Mathur AK. Effect of diazinon on male rats. Histopathological and biochemical studies. Environ.physiol.Biochem1975; 5:239-299.

[6] Urban JA D'Souza, Narayana K. Induction of seminiferous tubular atrophy by single dose of 5-Fluorouracil (5-FU) in Wistar rats. Indian J Physiol pharmacol 2001; 45(1):87-94.
[7] Narayana K, Urban JA D’Souza, Sanyal AK, Seetharama Rao KP. 5-Fluorouracil (5-FU) induces the formation of giant cells and sloughing of seminiferous epithelium in the rat testis. Indian J Physiol Pharmacol 2000; 44 (3):317-322.

[8] Urban JA D’ Souza. Effect of tamoxifen on spermatogenesis and tubular morphology in rats. Asian J Androl.2004; 6:223-226.

[9] Nakai M, Hess RA. Morphological changes in the rat sertoli cell induced by the microtubule poison carbendazim. Tissue and Cell 1994; 26:917-927.

[10] Nakai M, Hess RA, Netsu J Nasu T. Deformation of the rat sertoli cell by oral administration of carbendazim. Journal of Andrology 1995; 16:410-416.

[11] Urban JA D’Souza. Tamoxifen induced multinucleated cells (symplasts) and distortion of seminiferous tubules in rat testis. Asian J Androl 2003; 5:217-220. 